\title{
Role of Customer IQ in Product Innovation
}

\author{
Thomas George \\ D'Well Research, India \\ thomas@dowellresearch.com
}

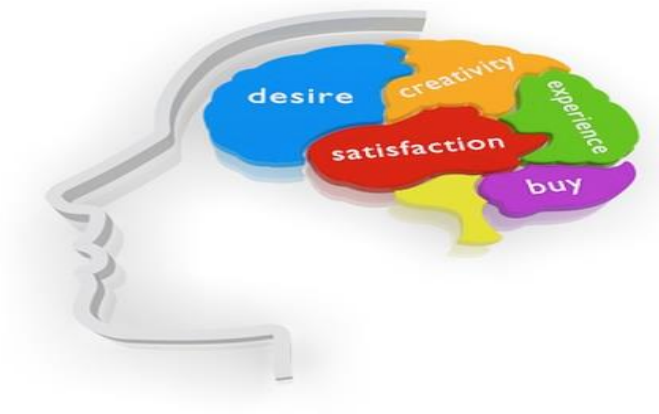

\begin{abstract}
Product innovation is not just technological innovation; it is a market oriented approach with upgradation of all the elements of marketing mix of the product. The marketing mix is a set of seven variables i.e. Product, Place, Price, Promotion, People, Process and Physical evidence which is upgraded and the same can be launched as the upgraded product. Customers' taste and behaviour changes from time to time, so for market oriented innovation to succeed; market information is necessary. Market information is collected using the internal or statistical method and external method. Companies take their Strategy decisions using this information. Both methods are used by companies to launch innovative products to the target market. In this approach, the product must address the demands of the customer. Innovation differentiates a product from its competitors for the customer. So When an Innovative product is introduced to a market, the customer uses the product based on his intellectual capacity. Customer takes the decision to purchase the product based on his thinking and analysis of the product. Here Customer IQ is reflected in the Customer purchase behaviour. As per the Lavidge and Steiner model, customer purchase decision is made up of awareness, knowledge, liking, preference, conviction and purchase. Hence Customer IQ plays an important role in Product Innovation. Customer IQ can be measured by calculating the cognitive ability of the customer to understand the product. In order to Grade customer IQ, D'Well research conducted a mall case study on 200 visitors'. The result shows that the Customer IQ of visitors is less than Normal IQ of population. The conclusions are Customer is not just demographic; they have ability to think, analyse \& conclude and companies have to move away from their beaten paths.
\end{abstract}

\section{Introduction}

Product innovation is nowadays talked about more than ever before. We hear about companies introducing innovative products to the market almost on a weekly or monthly basis. In this scenario, the question that inevitably comes to our mind is what exactly is product innovation? Innovation is a term denoting creativity and new ideas and its application.

Journal of Research in Administrative Sciences (JRAS)

VI(I), 17-23, ISSN:2664-2433

\section{Product Innovation Methods}

There are many ways to do product innovation, but here we focus attention on two prominent ways, as the innovation focal object and its impact. One way is Technological innovation and another is Market oriented innovation. Technological innovation of a product is the modification made to technical attributes of a product while Product innovation has a broader meaning, particularly in a business context. In this context, Product innovation is not 
just about technological modification; it represents the Upgradation of all elements of the marketing mix.

\section{Marketing mix and market oriented innovation}

Marketing mix consists of a set of marketing tools namely Product, Place, Price, Promotion, People, Process and Physical evidence. They are collectively regarded as the 7

P's of marketing. The businesses use the marketing mix to pursue marketing objectives in the target market.

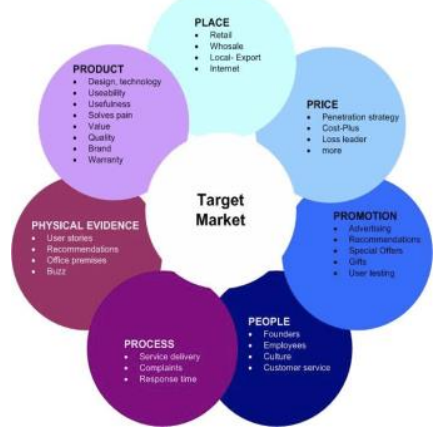

All the seven elements of the marketing mix are directed towards customers of the product in the target market. Hence, the upgrading of these seven elements is known as the market oriented approach in product innovation. In this approach, the product should address the demands of the customers. Customer's tastes and wants tend to change over time. So the businesses have to study carefully the needs, tastes and wants of the customer. Therefore, a product is tested for user experiences before its introduction to the target market. Here, we get that Product innovation can be validated only through the market oriented approach. So In a business context, the market oriented approach of innovation is regarded as higher than the technological approach in innovation. Market oriented approach of innovation can succeed only by getting information about the market and competitors.

\section{Market research and Product innovation}

Market oriented Product innovation relies on two methods for obtaining market information. The first one is external method and other is the Internal or the Statistical method. In the internal method, the information we get from respondents is analysed and decisions are taken internally by the research analysts for the organisation. In the external method, the strategy decisions are based on knowledge acquired from the respondents through interview. For example information or knowledge acquired from a doctor or a chartered accountant about their profession through interview. Both methods are used widely by companies to develop innovative products for the target market.

\section{How Customer IQ is related to Innovation?}

Innovation differentiates a product from its competitors, so how is Customer IQ related to Innovation? For instance when an innovative product is introduced into a market, the customer uses the product based on his idea or conception of the product. The understanding is based on his intellectual capacity. He uses the product in different ways; here we see that the customer's IQ plays an important part in innovation and gives its own contribution to innovation.

\section{Mapping the Customer behaviour using Lavidge and Steiner model}

The functioning of customer IQ reflects in the behaviour of the customer. So, the behaviour of a customer or the reasons behind the purchase decision of the customer can be fully understood by mapping the purchase journey of the customer using the Lavidge and Steiner model. The six steps are

1. Awareness - Awareness of product from different channels mainly advertisements.

2. Knowledge - Acquires knowledge about the technology or different features of the product. For example through the Internet or a retail advisor.

3. Liking - Develops a favourable attitude towards the product or its features.

4. Preference - Prefers the said product over other brands or substitutes in the market. He prefers the product due to its unique features.

5. Conviction - Customer develops opinion that the product is good enough and meets his needs and requirements. He is sure that the product meets all his conditions and satisfies his wants.. He is convinced it is a safe purchase.

6. Purchase- The customer makes the actual purchase.

In the Customer purchase journey, all the six steps are more or less related to the IQ level of the Customer. We get that the Customer is not just demographic; they have ability to think, analyse and conclude.

\section{Defining Customer IQ and its impact on business}

Customer IQ is a method based on customer intelligence in order to grade the intellectual ability of a customer to assess the product to match their own needs.

Customer IQ is useful for the company to arrive at a conclusion on the understanding power of a customer who uses their product.

Customer IQ helps us to acquire deeper insights about the customer. So businesses can service the customers better and helping them to deliver better outcomes.

Customer IQ has become a necessary input for New product development, Design product advertisements, Instruction manual on usage, Packaging design and After sales service.

\section{How to measure Customer IQ}

Customer IQ is measured by calculating the cognitive ability of a customer to understand the product. It is 
calculated by using a questionnaire focusing on the customer's capacity to understand the Product's utility, Price affordability, and Distribution channel, Reliability of advertisements, Physical appearance and people behind the product. In the Questionnaire, Assign different weightage points for all answer options to calculate the Customer IQ of the respondents. The sum total of the weightage points for each respondent gives the Individual Customer IQ. Using this method, the companies can find out which percentage of the population has a certain level of IQ. The Customer IQ, thus derived can be used by the company to do market segmentation based on IQ and also to prepare marketing Strategies based on IQ. The method can be used by companies to boost their businesses. The largest group of customers with a particular IQ can be derived using this method and businesses can target this segment. Customer grading based on their IQ is a form of Psychographic segmentation.

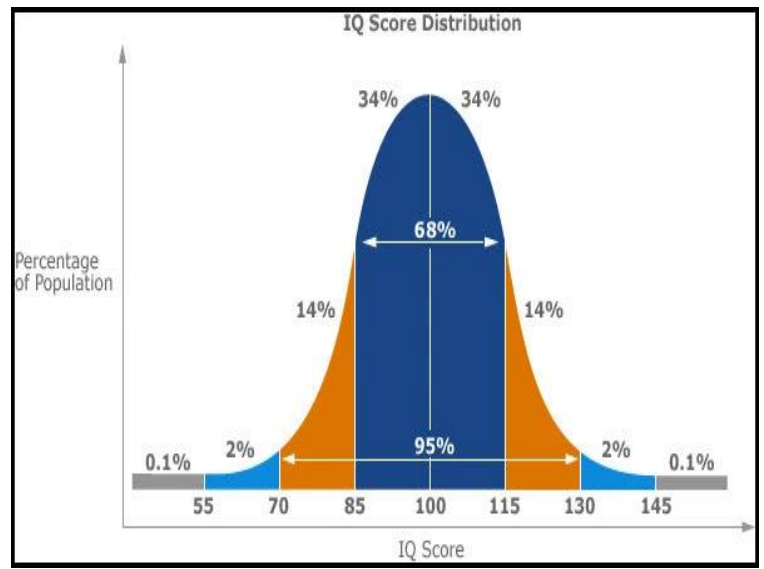

Graph shows Typical IQ Level of Population.

In the above Graph X-axis shows IQ score of the Population and $\mathrm{Y}$-axis shows percentage of population. The mean IQ score is 100 . Here we get a bell curve which shows the normal IQ Score distribution of the population. The curve shows that $68 \%$ of the population have an IQ score between 85 and 115 .

Companies assume the same Bell curve of the IQ level of population for their selected customer segments which is an ideal scenario, but the reality is customer IQ varies with their age and background. The actual curve is either skewed towards the right or to the left as seen in the below graph. Companies must focus on this part which represents the Customer IQ to maximise the business gains.

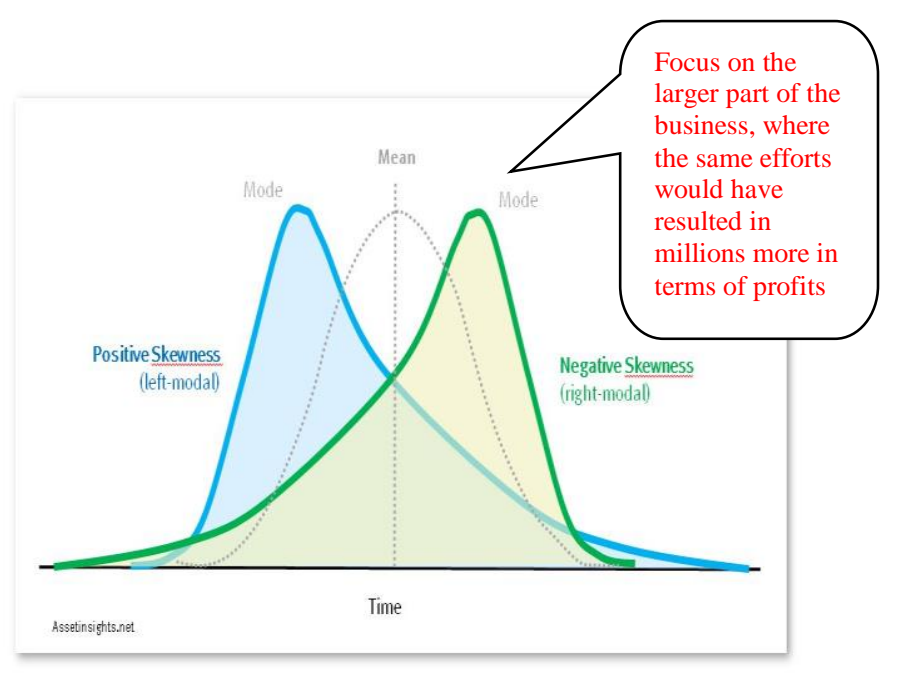

Distinction between Normal IQ and Customer IQ

Normal IQ is measured by calculating the analytical or cognitive abilities of a person in relation to their age group. The IQ is calculated using the equation Mental Age / Chronological Age x 100. Here, Mental age is your cognitive abilities relative to what others can do of different ages. For example If a child who is 10 year old can do only things which can be done by others of the same age, then his mental age is 10 but if he can do things done by a 25 year old man, then his mental age is 25 . So using the above equation, $10 / 10 \times 100=100$, which is the normal IQ. All Studies have shown that about $68 \%$ of the population have an IQ between 85 and 115 which is the normal IQ range and the average Normal IQ is 100 which are derived by taking the midpoint of the normal IQ range.

Customer IQ is the understanding or cognitive ability of a person to use a product. The method used to measure Customer IQ is the same as Normal IQ, but in business context. It is calculated by using a questionnaire based algorithm to calculate the overall ability of a customer to understand the product's usefulness, affordability, distribution channel, reliability of advertisements, after sales service, design etc. We have to assign different weightage to the answer options. The sum total of all the weightage points for each question gives Individual Customer IQ .The Average Customer IQ can be calculated by taking the mean of the Customer IQ score range corresponding to the maximum number of customers. For example, Let's assume that average IQ score range for visitors of a mall is 70-74 corresponding to the maximum number of people say 25, then we can determine the average customer IQ by taking the mean of 70-74 which we get here as 72. Customer IQ in a business context is very helpful for companies to understand and target their customers better based on their tastes and considerations. 


\section{Differentiation of Customer IQ from Customer Experience}

Is there any difference between Customer IQ and Customer experience? Customer IQ and Customer experience are at times confused. Though connected terms, they actually reflect two different facets of the customer in a purchase journey. In a customer purchase Journey; Awareness, Knowledge, Liking, Preference are based on cognitive or thinking behaviour. Customer IQ reflects this facet. The last two Conviction and Purchase are based on emotional feeling of customer created from initial analysis. Customer experience reflects this part.

\section{Calculation of Customer IQ - A Case Study}

D'Well Research conducted a Case study on IQ level of mall visitors

\section{Objective}

The study was conducted with the objective of finding the customer IQ in order to grade the intellectual ability of customers to evaluate the product to match their own needs.

\section{Methodology}

Data was collected from visitors at 5 malls in India. We collected data using a Questionnaire that contained questions regarding age, product utility, price affordability, distribution channel, reliability of advertisements, manufacturing process, physical appearance and people behind the product. The total sampling was 200, stratified random sampling method was used by keeping Mall, age and gender as equal strata.

\section{Illustration from Mall Case study}

(With sample Values)

As a representative case, we are taking a sample customer who visited mall in Chennai. We had recorded the following answers for the questionnaire given below ( Note : weightage points are given along with options, these points are time tested and were arrived based on detailed evaluation of psychological attributes, field testing and statistical trends)

\section{Part A - Profile}

* Respondent's age. Options 1. M 14-20 $\quad$ 2. M 21-30 $\quad 3 . \mathrm{M} 31-40 \quad$ 4. M 51-60

A. F 21-30

* Do you visit other malls in the city? Options 1. Yes, more often this mall 2. Yes, but rare 3. No
A. Yes, But rare
* Name of the mal
A. Phoenix market city, Chenna

* How often do you visit this mall?

Options 1. First time 2. More than once in a week 3. Once in a week

$$
\text { 4. Once in a month 5. Rarely }
$$

A. Once in a month

* Did you come alone? friends
Options 1. Yes, Alon
2. With family
3. With

A. With friends

* What have you done or going to do in this mall today? $<$ br $/>$ (rank based on response)

Options 1.Cafe/lounge eat food 2. Pub/disc 3 . Watching movie

4. Other entertainments for you or family

$5 . \quad$ Purchase accessories

(handbags/belts/junk Jewellery)

6. Purchase body care services (spa, saloon, beauty and parlour))

7. Purchase Clothes and Footwear

basic need (supermarket)

8. Purchase consumer goods /every day

9. Purchase electronic goods (TV, AC)

10. Purchase mobile phone 11. Purchase

sports goods

12. Not purchase anything, just time pass

A. Purchase clothes $<1>$

* What tempts you to visit this mall for these needs selected above? <br/>(rank based on responses)

Options 1. Service Quality \& support services

2. World class Brands \& services 3. Everything under one roof

4. Product varieties

5. Reliability of products and services

6. Near to my home/office

7. Other amenities like wash rooms, parking

etc. available in other places)

8. Exclusive products

(The products/brands i need is not

9. Good ambience 10. Other

A. Everything under one roof $-<1>$, Product varieties- $<2>$, Good ambience- $<3>$

* How do you find shop/restaurant/games/movie/ etc in this mall you are looking for? <br/> (rank based on responses)

Options. 1. Ask customer care 2. Ask other visitors 3. Look to floor map of mall

4. You know where it is, from previous visits 
A. You know from where it is, from previous visits$<1>$

* Have you done any online search before you came to the mall today?

Options 1. Yes 2. No

A. No

* Have you got any message (SMS, Whatsapp, email, call etc) from this mall or shops in this mall before came today (select all response)

Options 1.Sms 2. Whatsapp 3. Email 4. Phone call 5. No

A. No

* About your phone (most used if they have more than one)

Options 1. Brand- 2. Model-

A. 1. Nokia 2. asha 500

* When did you purchase this phone?

Options 1. Before 2006 2. $2006 \quad$ 3. 2007 4. 2008

5. 2009 6. 2010 7. 2011

2016

8. 201292013 10. 2014 11. 201512.

A. 2014

* Service providers (SIM)

Options 1. For calling- $\quad$ 2. For Internet-

A. 1. Vodafone 2. Vodafone

* Have you taken part in any market research survey in the last 6 months?

Options 1. Yes 2.No

A. No

* Do you or any of your friends/relatives work in any of these trades/professions?.

Options 1.Market research 2. Marketing 3. Advertising

4. Manufacturer/distributor/retailer 5. Management consultant

6. Journalism 7. Public relations 8. Event management

9. None of the above (select all that apply)

A. None of the above

\section{Part B - IQ}

* Tell me about a high value product you recently bought.1. Product name- 2. Brand/shop name-

A. 1. Clothes 2..Wrangler
* Price of the product :

Options 1. $1000-5000$ 2. 5000-10,000 3 .

10,000-25,000 4. 25,000-50,000

5. 50,000-1 lac 6. 1 lac-5 lac, 7. 5 lac-10

lacs 8. Above 10lacs)

A. $1000-5000$

* When you bought it?

Options 1 . This week 2. Two weeks back 3. One month back 4 . Six months back

A. One month back

* Did you buy this <product> to fulfil your STATUS? If so what percentage $(0-9->100,10-$ 19->90, 20-29->80, 30- $39->70,40-49->60,50-$ 59->50, 60-69 ->40, 70-79->30,80-89->20,90$100->10)$

(100) percent- 10

* This $<$ Product $>$ was matching with my Needs $<>$ percent (0-9->10, 10-19->20, 20-29->30, 30-39$>40,40-49->50,50-59->60,60-69->70,70-79-$ $>80,80-89->90,90-100->100)$

A. (100) percent - 100

* Price of this < Product> depended on Brand / Shop $<>$ percent (0-9->100, 10-19->90, 20-29$>80$, 30-39->70, 40-49->60, 50-59->50, 60-69$>40,70-79->30,80-89->20,90-100->10$ )

A. (100) percent - 10

* Price of this < Product $>$ depended on Quality $<>$ percent (0-9->10, 10-19->20, 20-29->30, 30-39$>40,40-49->50,50-59->60,60-69->70,70-79-$ $>80,80-89->90,90-100->100)$

A. (100) percent - 100

* I bought this <Product> only because was available in discounts

Options 1 . Yes -10 2. No -80

A. Yes -10

* I believe $<>$ percentage of what I saw in advertisements of this <product $>(0-9->100,10-$ 19->90, 20-29->80, 30-39->70, 40-49->60, 5059->50, 60-69->40, 70-79->30, 80-89->20, 90$100->10)$

A. (100) percent - 10 
* Before you bought this, did u look at the label/manual for the details about the manufacturer?

Options 1. Yes - 100 2. No - 0

A. Yes -100

* Before you bought this <Product $>$, did you check the Quality of " after sales service and warranty period"?

Options 1. Yes - 100 2. No - 0

A. Yes -100

* Before you bought this < Product $>$, did you check other competitive product's features?

Options 1. Yes - 100 2. No - 0

A. Yes -100

When you saw this $<$ Product $>$ for purchase

Options 1. I believed in brand/shop - 30

product - 100

2. I believed only after experiencing the

A. I believed in brand/shop - 30

* When you saw this $<$ Product $>$ for purchase Options 1. Looked at the brand/logo only/Trust the shop - 30

2. Read the label/manual for manufacturing/technology - 100

A. Read the label/manual for manufacturing process/technology -100

* When you saw this $<$ Product $>$ for purchase Options 1. Looked at usage terms and Manuel for how to use - 100

2. Asked salesman about the usage terms and how to use - 50

A. Asked salesman about usage terms and how to use - 50

* Before you bought this <product> how did you learn about this <product $>$

Options 1. From salesman - 50

2. From online - 100

A. From salesman - 50

- How often did you use this <product>

Options 1.Daily - 100

2. One/two times in a week - 70
3. Once in two weeks - 50

4. Once in a month - 20

5. Not used - 0

A. Once in two weeks - 50

For each of the questions regarding product utility, price affordability, distribution channel, reliability of advertisements, manufacturing processes, physical appearances and people behind the product, we got values as given below

10, 100,10,100,10,10,100,100,100,30,100,50,50 \&50

Now we Add up all the values $\{10+100+10+100+10+10+100+100+100+30+100+50+50$ $+50\}=\{\underline{820}\}$ is the total. Here we got the Customer IQ as 82.

With Customer IQ of sample being 82 and average Normal IQ of population is 100, we can say that the Customer IQ of the visitor is significantly lesser than the normal IQ of population.

Following histogram shows the customer IQ distribution of total sampling

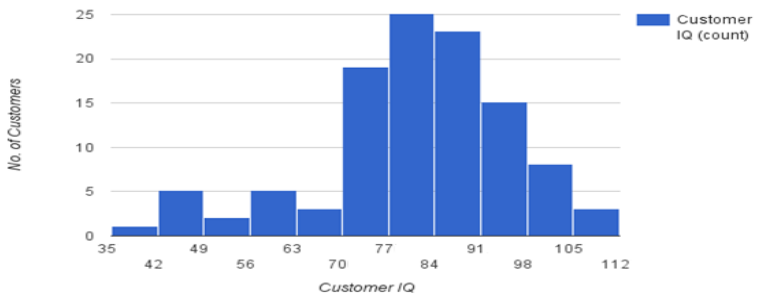

From the above Graph, we conclude that the average Customer IQ of the mall visitors is between 77-84.

\section{Results of the Case Study}

When we compare the result of this study with "normal IQ" distribution, it shows that the mean, mode and median of "customer IQ" of mall visitors is less than the "normal IQ" of population

Relevance of customer IQ in different business sectors 


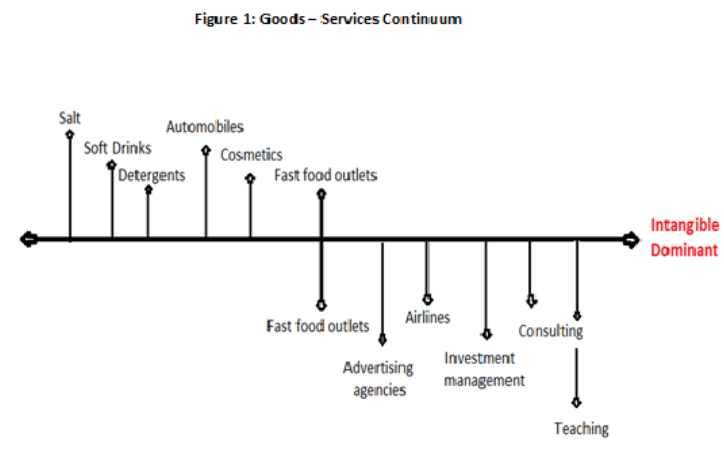

Relevance of customer IQ

In the above scale we can see significant differences in the relevance of Customer IQ for respondents from the Goods sector (tangible dominant) and the respondents from the Services sector (intangible dominant). We experienced that the relevance of Customer IQ was high for the services sector as a whole but its influence was seen to be most high in the Teaching and Consulting segments and less in the Investment Management, Airlines and Advertising segments. The role of Customer IQ was evidently less in the goods sector as a whole.

\section{Conclusion}

In this age, Companies are at the center of Innovation, it is through them New Technologies, Inventions, products and Ideas come to the market. Companies have to be aware of the importance of Innovation in the competitive scenario. In this competitive back ground, companies have to make decisions on innovation of the product and the processes. For such decision making the companies need to have a better understanding of the process through which the customer makes his purchase decision and the role of customer IQ in the purchase decisions. To thoroughly research this issue, we chose the subject the role of Customer IQ in Product innovation as the topic of research.

This research confirms that customers are capable of making purchase decisions independently based on their thinking, analysis and conclusions. The main outcome of this study is companies have to move away from the beaten path. It underscores that Customer IQ is an inevitable input for new product development, designing product advertisements, Instruction manual for usage, packaging design and after sales service. The biggest impact will be on the Companies as they will now have to look beyond their R\&D development centers for Innovation. Companies have to work with customers to foster innovation.

\section{References}

i. Year -1961, Author - Robert J. Lavidge and Gary A. Steiner, Work- "A model for Predictive Measurements of Advertising Effectiveness", Journal of Marketing, Description Of Model HIERARCHY OF EFFECTS-Awareness, Knowledge, Liking, Preference, Conviction, Purchase

ii. Year - 1960, Author- Jerome E. McCarthy, Work- "Basic Marketing: a Managerial Approach", Description of ModelMarketing Strategy Planning

iii. Year - 2003, Author- Becker, K.A, Work- "History of the Stanford-Binet Intelligence scales: Content and psychometrics "Description of Model- Innovations in Intelligence testing and psychological assessment. 